\title{
Оценка направлений поставок редкоземельной руды месторождения Томтор на переработку: пространственный аспект*
}

В.А. ЯЦЕнко. E-mail: yva@ieie.nsc.ru

Я.В. КРЮКОВ, кандидат экономических наук, Институт экономики и организации промышленного производства СО РАН, Новосибирск. E-mail: kryukovyv@ieie.nsc.ru

Разработаны и предложены варианты альтернативных транспортных направлений к перерабатывающим мощностям на территории регионов Сибири и Дальнего Востока, на базе которых есть возможность организации химико-металлургического комбината для обогащения редкоземельных руд месторождения Томтор, расположенного в Республике Саха (Якутия). Проведен сравнительный анализ вариантов, связанный с технологическими и экономическими преимуществами возможных мест локализации переработки сырья и последующего получения высокотехнологичной продукции на основе редкоземельных металлов.

Ключевые слова: Томтор, редкоземельные металлы, оксиды редкоземельных металлов, ГК «Росатом», ГК «Ростехнологии», высокотехнологичная продукция, сравнительный анализ, пространственный анализ

Редкоземельная промышленность начинается с месторождений и заканчивается применением высокотехнологичной продукции в глобальной экономике. Одним из промежуточных этапов является формирование эффективных и экономичных вариантов транспортировки исходного редкоземельного сырья до мест переработки и получения высоколиквидной товарной продукции. В этой связи экономистами подчеркивалось, что «необходимы целенаправленные шаги и меры по созданию в городах Сибири и Дальнего Востока кластеров и цепочек создания повышенной добавленной стоимости на основе использования РЗМ» [1].

Сегодня редкие и редкоземельные металлы (РЗМ) в России почти не добываются. Ценный редкозём у нас есть, а добычи и переработки - практически нет. В России есть только одно место добычи - Кольский полуостров. Получаемый лопаритовый

* Работа выполнена по плану НИР ИЭОПП СО РАН в рамках проекта XI.174.1.2. «Стратегические направления реализации потенциальнойценности минерально-сырьевых ресурсов Азиатской части России в условиях глобальных вызовов XXI века» 
концентрат отправляется на Соликамский магниевый завод (Пермский край), производственные мощности которого ограничены 10-12 тыс. т в год. Его готовая продукция - плав хлоридов РЗМ и дезактивированные карбонаты (концентраты) РЗМ - промежуточные продукты чистых оксидов РЗМ, почти весь объем которых идет на экспорт для дальнейшей переработки.

В постсоветский период перерабатывающие руду и концентрат заводы остались в странах ближнего зарубежья. При этом СССР занимал третье место по добыче редкоземельных металлов в мире, а сегодня доля современной России на глобальном рынке Р3М - всего 1,3\%, несмотря на то, что наша страна обладает 17-19\% от мирового запаса РЗМ (второе место после Китая [2].

Полная зависимость российской технологичной и высокотехнологичной промышленности от импортных (прежде всего, китайских) редкоземельных металлов не позволяет гарантировать бесперебойное снабжение этим стратегически важным сырьем в будущем. Чтобы государство было ресурсонезависимым, обеспечивало экономическую и национальную безопасность, добывающая промышленность РЗМ должна быть вертикально интегрированной с полной технологической цепочкой производства: «от лопаты до редких металлов или чистых оксидов РЗМ». А если говорить о программе импортозамещения, чрезвычайно актуальной сегодня для промышленности нашего государства, то - «до высокотехнологичной продукции, в которую включены те или иные редкие земли» [3].

Вот почему Томторское месторождение так важно для России! Оно является уникальным по своему составу и концентрациям двух десятков как традиционных полезных ископаемых (железо, фосфор, титан, ванадий), так и редких элементов (от лантана до высокодефицитных иттрия и скандия). Но визитной карточной Томтора являются редкие элементы: ниобий, иттрий, скандий и группа лантаноидов [4]. Практически каждый из них присутствует в весьма внушительных концентрациях, ранее не известных в мировой геологической практике, благодаря чему именно якутское месторождение в ряду уникальных ниобийредкоземельных объектов планеты заняло первое место. Запасы редких элементов в Томторском месторождении огромны и при нынешнем спросе могут обеспечить потребности России (а при определенных условиях - и мира) на сотни лет [5]. 
В Государственной программе «Развитие промышленности и повышение ее конкурентоспособности до 2020 года» (от 2013 г.) [6], ответственным исполнителем которой является Министерство промышленности и торговли РФ, поставлена глобальная цель: создать в Российской Федерации конкурентоспособную редкоземельную промышленность полного технологического цикла для удовлетворения потребностей отечественного оборонно-промышленного комплекса, гражданских отраслей и выхода на зарубежные рынки. В этой программе особую роль отводят Томторскому месторождению.

Сейчас известно, что владелец месторождения - компания «ТриАрк Майнинг» (совместное предприятие ГК «Ростехнологии» и Группы «ИСТ») планирует разместить химико-металлургическое производство для переработки томторских руд, используя, в том числе, территорию Приаргунского производственного горно-химического объединения в Краснокаменске (Забайкальский край) - Краснокаменский гидрометаллургический комбинат [7]. По крайней мере, соглашение о строительстве комбината с правительством края заключено весной 2016 г.

Объем инвестиций требует детального изучения. Но уже сейчас имеются оценки, по которым проект по годовой переработке 100 тыс. т руды томторского месторождения при сложившихся курсе валюты и внешней экономической конъюнктуре обойдется не менее чем в 70 млрд руб. По крайней мере, такую оценку дает директор Института геологии и минералогии СО РАН академик РАН Н.П. Похиленко [8]. При максимальной проектной мощности в 150 тыс. т инвестиции составят не менее 100 млрд руб.

Предполагалось, что проект будет финансировать Внешэкономбанк. Но из-за западных санкций он сейчас испытывает нехватку средств, в частности для вложения в горнорудные проекты. Вместе с тем геологоразведочные работы высоких стадий, позволяющих в ближайшие два года начинать выемку руды, в настоящее время активно выполняются.

Всё пока идет к тому, что Краснокаменский гидрометаллургический комбинат является базовым вариантом для строительства первого звена технологической цепочки - производства дезактивированных карбонатов РЗМ [7]. Но место переработки может быть пересмотрено в любой момент по различным причинам: экономическим, политическим, технологическим и т. п. 
Поэтому имеет смысл обратиться к анализу других потенциальных предприятий атомной промышленности Сибири и Дальнего Востока (ГК «Росатом»), на площадках которых можно создать как первые звенья цепочки производства, так и последнее звено - выпуск редкоземельных оксидов или чистых разделенных металлов [9]. В результате мы сможем предложить альтернативные варианты маршрутов транспортировки руды от удаленного месторождения, находящегося в Арктической зоне, до этих предприятий.

\section{Потенциальные предприятия по обогащению томторской руды}

Сегодня атомная отрасль России представляет собой мощный комплекс из более чем 400 предприятий и организаций, входящих в состав Государственной корпорации «Росатом». По роду деятельности нас будут интересовать предприятия Уранового холдинга «АРМЗ» («Атомредметзолото»), который является горнорудным дивизионом госкорпорации, и топливная компания «ТВЭЛ» (табл. 1). Эти предприятия входят в интегрированную компанию «Атомный энергопромышленный комплекс», которая в свою очередь обеспечивает полный цикл производства в сфере ядерной энергетики, от добычи урана до строительства АЭС и выработки электроэнергии [10].

\section{Таблица 1. Производственные структуры ГК «Росатом» (упрощенная схема)}

\begin{tabular}{|c|c|}
\hline & «Росатом» \\
\hline \multicolumn{2}{|c|}{ Атомный энергопромышленный комплекс (“Атомэнергопром») } \\
\hline \multicolumn{2}{|r|}{ «APM3» } \\
\hline \multirow{2}{*}{$\begin{array}{l}\text { Приаргунское производственное горно- } \\
\text { химическое объединение (ППГХО) }\end{array}$} & Переработка исходной руды \\
\hline & Получение коллективного карбоната РЗМ \\
\hline \multicolumn{2}{|r|}{ «ТВЭЛ» } \\
\hline \multirow{6}{*}{$\begin{array}{l}\text { Ангарский электролизный химический } \\
\text { комбинат (АЭХК) }\end{array}$} & Переработка исходной руды \\
\hline & Получение коллективного карбоната РЗМ \\
\hline & Извлечение тория и урана \\
\hline & Получение индивидуальных оксидов РЗМ \\
\hline & Получение чистых РЗМ \\
\hline & Производство высокотехнологичной продукции, содержащей РЗМ \\
\hline \multirow{2}{*}{ Сибирский химический комбинат (СХК) } & Переработка исходной руды \\
\hline & Получение коллективного карбоната РЗМ \\
\hline
\end{tabular}




\begin{tabular}{|l|l|}
\hline \multicolumn{2}{|c|}{ «Росатом» } \\
\hline \multicolumn{2}{|c|}{ Атомный энергопромышленный комплекс («Атомэнергопром») } \\
\hline $\begin{array}{l}\text { ПО «Электрохимический завод» } \\
\text { (ПО «ЭХЗ) }\end{array}$ & $\begin{array}{l}\text { Получение индивидуальных оксидов РЗМ } \\
\text { Получение чистых РЗМ } \\
\text { Производство высокотехнологичной продукции, содержащей РЗМ }\end{array}$ \\
\hline $\begin{array}{l}\text { Новосибирский завод химконцентратов } \\
\text { (НЗХК) }\end{array}$ & $\begin{array}{l}\text { Получение индивидуальных оксидов РЗМ } \\
\text { Получение чистых РЗМ } \\
\text { Производство высокотехнологичной продукции, содержащей РЗМ }\end{array}$ \\
\hline Горно-химический комбинат (ГХК) & $\begin{array}{l}\text { Переработка исходной руды } \\
\text { Получение коллективного карбоната РЗМ } \\
\text { Извлечение тория и урана } \\
\text { Хранение радиоактивных отходов } \\
\text { Получение индивидуальных оксидов РЗМ } \\
\text { Получение чистых РЗМ } \\
\text { Производство высокотехнологичной продукции, содержащей РЗМ }\end{array}$ \\
\hline
\end{tabular}

\section{Урановый холдинг «Атомредметзолото»}

Холдинг «АРМЗ» сегодня реализует ряд перспективных проектов по добыче урана, таких как «Хиагда» (Республика Бурятия) и «Далур» (Курганская область). К этому можно добавить ряд проектов в рамках программы диверсификации, связанных с добычей редких, редкоземельных и драгоценных металлов «Павловское» на архипелаге Новая Земля, добыча и переработка редких и редкоземельных металлов в Курганской области [11].

Холдинг «Атомредметзолото» трансформируется в «компанию развития» - динамичную, компетентную в производстве базовых и стратегических металлов и технологичную. Например, сформирована программа развития новых направлений бизнеса, создан промышленный парк «Краснокаменск», где шаг за шагом идут к созданию горно-металлургического кластера.

Якорным предприятием для новых, не связанных с урановым производством предприятий, станет Приаргунское производственное горно-химическое объединение (юг Забайкальского края) (см. табл. 1).

Сегодня предприятие не является прибыльным (так, в 2015 г. убытки составили 3 млрд руб). Это связано с тем, что мировой 
рынок урана насыщен - цены падают, снижаются объемы выработки продукции, растет себестоимость производства. Предприятие отработало уже 45 лет, и идет истощение запасов действующих урановых месторождений [12].

Одна из важнейших задач Приаргунского производственного горно-химического объединения - диверсификация производства и выход на безубыточную работу. Поэтому на территории Краснокаменска планируется организовать новые производства: заводы по переработке пиритных огарков, производству взрывчатых веществ, переработке концентратов цветных металлов, а также руд редких и редкоземельных металлов Томторского месторождения $[7,13]$. Поэтому активно привлекаются внешние инвесторы.

\section{Краснокаменский гидрометаллургический комбинат (на территории ППГХО)}

ППГХО является крупнейшим предприятием в Урановом холдинге «АРМЗ», а также градообразующим для города Краснокаменска, с избыточными производственными площадями и необходимой инфраструктурой (хвостохранилище, тепло-, электро-, водоснабжение, спецканализация, транспортная доступность). К 2018 г. ожидается полная реконструкция аэропорта в городе, а на данный момент между Читой и Краснокаменском курсируют небольшие самолеты Л-410 УВП-Е 20. Это самое ближайшее предприятие к потенциальным рынкам сбыта - Индии, Японии и Южной Корее, которые заинтересованы в новом производителе РЗМ (кроме Китая, как монополиста на рынке РЗМ).

Доставлять томторскую руду в значительных объёмах (от 10 тыс. т до 100-150 тыс. т в год) экономически и логистически выгодно следующим образом (рисунок):

- по зимнику реки Анабар с месторождения Томтор до посёлка Юрюнг-Хая ( $\approx 350$ км) автопоездами, который ежегодно «пробивается», так как в 80 км к западу от месторождения отрабатываются алмазные россыпи («Алмазы Анабара», входящее в АК «АЛРОСА») [14];

- затем по реке Лена от посёлка Юрюнг-Хая до Якутска ( 2000 км) судами смешанного класса «река - море», например транспортного предприятия «Ленское объединенное речное пароходство»;

- $\quad$ из Якутска до Краснокаменска ( $\approx 2700$ км) - железнодорожным транспортом. 




Варианты транспортных путей [2]

Суммарное расстояние от месторождения Томтор до КГК составляет около 5 тыс. км.

\section{Топливная компания «ТВЭЛ»}

Основной вид деятельности ТК «ТВЭЛ»- производство и поставки ядерного топлива для энергетических и исследовательских реакторов. Компания поставляет на российский и мировой рынки также широкий спектр неядерной продукции: цирконий, литий, кальций, магниты, тонкостенные трубы, полирующие порошки, сверхпроводниковые материалы и другую продукцию. На предприятиях ТК «ТВЭЛ» при поддержке собственных проектно-конструкторских и научно-исследовательских подразделений успешно функционируют гидрометаллургические, металлообрабатывающие, машиностроительные и прокатные производства [15].

В качестве плацдарма для строительства химико-металлургического комбината как альтернативы Краснокаменскому гидрометаллургическому комбинату для производства карбонатов РЗМ, в том числе для продолжения технологической цепочки до оксидов или чистых металлов РЗМ, высокотехнологичной товарной продукции нас будут интересовать следующие предприятия топливной компании (см. табл. 1). 
- Ангарский электролизный химический комбинат (Ангарск, Иркутская область);

- Сибирский химический комбинат (Северск, Томская область);

- ПО «Электрохимический завод» (Зеленогорск, Красноярский край);

- Новосибирский завод химконцентратов (Новосибирск, Новосибирская область).

Из вышеперечисленных предприятий по роду деятельности, развитой инфраструктуре, компетенциям больше всего подходят два предприятия: АЭХК (первый альтернативный вариант места размещения) и СХК (второй альтернативный вариант), которые мы рассмотрим далее.

Ангарский электролизный химический комбинат (АЭХК)

АЭХК - одно из градообразующих предприятий города Ангарска, которое расположено в 40 км от Иркутска и в 100 км от уникального природного объекта - озера Байкал. И это обстоятельство накладывает на предприятие особую ответственность перед окружающей средой.

Сегодня «ТВЭЛ» с правительством Иркутской области и промышленными и инжиниринговыми компаниями ведет диалог об открытии на базе АЭХК новых неурановых производств. На данный момент предприятие получает от реализации неядерной продукции около 4\% всей выручки [16].

Преимущества строительства химико-металлургического комбината для переработки томторских руд на базе АЭХК следующие [17]:

- $\quad$ огромные производственные площади для сдачи в аренду (20 тыс. м $^{2}$ - на промплощадке и 4 тыс. м $^{2}$ - вне территории) с инфраструктурой обеспечения необходимыми ресурсами (тепло-, электро-, водоснабжение, пар, сжатый воздух, жидкий азот, вентиляция, система спецканализаций);

- транспортно-логистическая инфраструктура: наличие железнодорожных путей и автомобильных дорог;

- электропитание с суммарной свободной мощностью 170 МВт и самой низкой стоимостью электроэнергии в РФ! 
Доставлять томторскую руду до АЭХК предлагается следующим образом (см. табл. 1):

- по зимнику с месторождения Томтор до посёлка Юрюнг-Хая ( $\approx 350$ км) автопоездами;

- $\quad$ затем по реке Енисей от посёлка Юрюнг-Хая до города Красноярска ( $\approx 4100$ км), например, судами класса «река - море» основного перевозчика по водным путям бассейна Енисея - «Енисейского речного пароходства»;

- из Красноярска до города Ангарска ( $\approx 1100$ км) - железнодорожным транспортом.

В этом случае общая протяженность путей составит около 5,5 тыс. км

\section{Сибирский химический комбинат (СХК)}

Вторым альтернативным вариантом строительства химико-металлургического комбината для переработки томторской руды является градообразующее предприятие города Северска «Сибирский химический комбинат» (Томская область). Помимо основной урановой СХК выпускает различную неядерную продукцию, в том числе фториды редкоземельных металлов [18].

СХК имеет все необходимые коммуникации для строительства химико-металлургического комбината (тепло-, электро-, водоснабжение), которые смогут обеспечить бесперебойное и эффективное функционирование производственного процесса. Открытым остается следующий вопрос: есть ли готовые производственные площади или их придется строить?

Доставлять томторскую руду до СХК предлагается следующим образом (см. рис. 1).

- по зимнику с месторождения Томтор до посёлка Юрюнг-Хая ( 2350 км) автопоездами;

- далее по реке Енисей от посёлка Юрюнг-Хая до Красноярска ( $\approx 4100$ км);

- от Красноярска до Северска ( $\approx 650$ км) - железнодорожным транспортом.

В таком случае общая протяженность маршрута составит около 5,1 тыс. км. Второй способ: напрямую от посёлка ЮрюнгХая до Северска по реке Обь - примерно 5,5 тыс. км.

\section{Железногорский горно-химический комбинат}

Третьим альтернативным вариантом строительства химико-металлургического комбината для переработки руды Томтора является уникальное предприятие с подземным расположением 
основных ядерных производств, не имеющее аналогов в мире: градообразующее предприятие города Железногорска Красноярского края - Горно-химический комбинат (ГХК) [19].

Преимущества этого варианта заключаются в том, что здесь созданы комплекс сооружений и коммуникаций, полная транспортно-логистическая инфраструктура, к тому же здесь имеются все необходимые компетенции для работы производства такого типа. Например, утилизация радиоактивных элементов и хранение отходов, конструирование технологического оборудования и его техническое обслуживание. На этом предприятии есть технологии по разделению тория и монацитового песка.

Уже не раз прозвучала оценка руководства «Росатома», что на Горно-химическом комбинате самая высокая в отрасли эффективность реализации проектов. Так почему бы этим не воспользоваться?

Доставлять томторскую руду до ГХК предлагается следующим образом (см. рисунок):

- по зимнику от месторождения Томтор до посёлка Юрюнг-Хая ( $\approx 350$ км) автопоездами;

- $\quad$ затем по реке Енисей от посёлка Юрюнг-Хая до города Железногорска ( $\approx 4000 \mathrm{~km})$.

Из рассмотренных вариантов транспортировки томторской руды это самый короткий путь от месторождения до возможного места строительства химико-металлургического комбината около 4,3 тыс. км.

В таблице 2 приведены суммарные протяженности различных вариантов транспортировки томторской руды.

\section{Таблица 2. Оценка расстояний маршрутов транспортировки руды с месторождения Томтор различными видами транспорта до места ее переработки и получения высокотехнологичной РЗМ-продукции}

\begin{tabular}{|l|l|c|c|}
\hline Пункт отправления & Пункт назначения & Расстояние, км & Вид транспорта \\
\hline \multicolumn{5}{|c|}{ Томтор - ППГХО } \\
\hline Томтор & п. Юрюнг-Хая & 350 & Автопоезда \\
\hline п. Юрюнг-Хая & г. Якутск & 2000 & Морской \\
\hline г. Якутск & г. Краснокаменск & 2700 & Ж/д \\
\hline итого & & \multicolumn{2}{|c|}{$\mathbf{5 0 5 0}$} \\
\hline
\end{tabular}


Окончание табл. 2

\begin{tabular}{|c|c|c|c|}
\hline Пункт отправления & Пункт назначения & Расстояние, км & Вид транспорта \\
\hline \multicolumn{4}{|c|}{ Томтор - АЭХК } \\
\hline \multicolumn{4}{|c|}{ Вариант 1: п. Юрюнг-Хая - г. Красноярск } \\
\hline Томтор & п. Юрюнг-Хая & 350 & Автопоезда \\
\hline п. Юрюнг-Хая & г. Красноярск & 4100 & Морской \\
\hline г. Красноярск & г. Ангарск & 1100 & Ж/д \\
\hline \multicolumn{2}{|l|}{ итого } & \multicolumn{2}{|c|}{5550} \\
\hline \multicolumn{4}{|c|}{ Томтор - СХК } \\
\hline \multicolumn{4}{|c|}{ Вариант 1: по реке Обь } \\
\hline Томтор & п. Юрюнг-Хая & 350 & Автопоезда \\
\hline п. Юрюнг-Хая & г. Северск & 5100 & Морской \\
\hline \multicolumn{2}{|l|}{ итого } & \multicolumn{2}{|c|}{5450} \\
\hline \multicolumn{4}{|c|}{ Вариант 2: по реке Енисей } \\
\hline Томтор & п. Юрюнг-Хая & 350 & Автопоезда \\
\hline п. Юрюнг-Хая & г. Красноярск & 4100 & Морской \\
\hline г. Красноярск & г. Северск & 650 & Ж/д \\
\hline \multicolumn{2}{|l|}{ итого } & \multicolumn{2}{|c|}{5100} \\
\hline \multicolumn{4}{|c|}{ Томтор - ГХК } \\
\hline Томтор & п. Юрюнг-Хая & 350 & Автопоезда \\
\hline п. Юрюнг-Хая & г. Железногорск & 4050 & Морской \\
\hline \multicolumn{2}{|l|}{ итого } & \multicolumn{2}{|c|}{4400} \\
\hline
\end{tabular}

Таким образом, рассмотрены перспективные предприятия российской атомной промышленности, на базе которых можно построить химико-металлургический комбинат для переработки руд месторождения Томтор, в качестве альтернативы Краснокаменскому гидрометаллургическому комбинату на базе ППГХО:

- Ангарский электролизно-химический комбинат, Ангарск, Иркутская область;

- Сибирский химический комбинат, Северск, Томская область;

- Горно-химический комбинат, Железногорск, Красноярский край.

Если разбить технологическую цепочку на два или более этапов: руда - концентрат и оксиды РЗМ - оксиды и индивидуальные РЗМ - высокотехнологичные товарные изделия, то далее 
следует задействовать ещё два завода с развитой инфраструктурой, входящих в структуру «ТВЭЛ»:

- Новосибирский завод химконцентратов (ПАО «НЗХК»), г. Новосибирск, Новосибирская область;

- Производственное объединение «Электрохимический завод» (ПО «ЭХЗ»), ЗАТО Зеленогорск, Красноярский край.

Помимо основных видов деятельности (изготовление топлива для АЭС и исследовательских реакторов России и мира), НЗХК производит чистый металлический литий и его соли (например, для производства аккумуляторов), цеолитные катализаторы, которые потом поставляют не только на отечественный, но и на зарубежные рынки. А ПО «ЭХЗ», помимо основных видов деятельности (обогащение и разделение изотопов урана), дополнительно производит изотопы различных элементов, фтористые соединения.

На каждом предприятии, входящем в структуру топливной компании «ТВЭЛ», есть различные неядерные производства, представленные широким спектром продукции. Поэтому любое такое предприятие можно включить в технологическую цепочку для производства оксидов РЗМ, индивидуальных РЗМ и производства высокотехнологичной продукции, содержащей РЗМ.

\section{Заключение}

В статье нами рассмотрены и продемонстрированы альтернативные варианты транспортировки добытой с месторождения Томтор руды на крупные технологические предприятия «Росатома» Сибири и Дальнего Востока, которые могут перерабатывать сырье как до первой стадии передела (концентрат РЗМ), так и до последующих (оксиды металлов и индивидуальные РЗМ).

Понятно, что доставлять и перерабатывать томторскую руду до концентрата РЗМ экономически и логистически выгодно на предприятиях, расположенных на минимальном удалении от месторождения. Но получать последующие переделы и высокотехнологичную продукцию, использующую РЗМ, можно на любом предприятии России. Ведь транспортные издержки в таком случае будут составлять, по нашим расчетам, не более $3-5 \%$.

Нельзя допустить, чтобы карбонаты РЗМ с Краснокаменского гидрометаллургического комбината в полном объеме экспортировались. Необходимо создать всю технологическую 
цепочку в пределах нашей страны. И для этого у нас всё есть: растущий внутренний спрос, предприятия с нужными технологическими компетенциями, на которых есть возможность создать производство, транспортная инфраструктура и т. п. Будет стратегической ошибкой, имея такое уникальное по мировым меркам месторождение, импортировать Р3М, в то время как Россия может сама стать экспортером.

Что же касается санкций западных стран и сегодняшней политической конъюнктуры в мире, то они побуждают Российскую Федерацию развивать собственную промышленность и уходить от импорта. Поэтому очень важно сейчас объединить все усилия и заинтересованные стороны: государство, промышленность, науку, инвесторов, чтобы выработать единую стратегию для создания полного технологического цикла производства чистых оксидов РЗМ. Ведь для страны это вопросы не только прибыли и национальной безопасности, но и суверенитета, так как РЗМ применяются во всех без исключения высокотехнологичных отраслях промышленности.

\section{Литература}

1. Крюков В.А., Толстов А.В., Самсонов Н. Ю. Стратегическое значение редкоземельных металлов в мире и в России // ЭКО. - 2012. № 11. - C. 5-16.

2. Яценко В.А. Оценка приоритетности направлений транспортировки руды ниобий-редкоземельного месторождения Томтор на потенциальные предприятия ее обогащения // Север и Арктика в новой парадигме мирового развития. Лузинские чтения - 2016 / Под общ. ред. Е. П. Башмаковой, Е. Е. Торопушиной; Кольский науч. центр РАН, Ин-т экон. проблем им. Г.П. Лузина Кольского, - Апатиты: ИЭП КНЦ PAH, 2016. - C. 254-257.

3. Толстов А. В., Самсонов Н. Ю. Томтор: геология, технологии, экономика // ЭКО. - 2014. - № 2 (476). - С. 36-44.

4. Делицын Л. М., Мелентьев Г. Б., Толстов А. В., Магазина Л. А., Самонов А. Е., Сударева С.В. Технологические проблемы Томтора и их решение // Редкие земли. - 2015. - № 2 (5). - С.164-179.

5. Похиленко Н. П., Крюков В.А., Толстов А. В., Самсонов Н. Ю. Томтор как приоритетный инвестиционный проект обеспечения России собственным источником редкоземельных элементов // ЭКО. - 2014. - № 2 (476). - С. 22-35.

6. Государственная программа Российской Федерации «Развитие промышленности и повышение ее конкурентоспособности» [Эл. ресурс]: Постановление от 15.04.2014 г. № 328 . 
URL: http://government.ru/media/files/1gqVAlrW8Nw.pdf (дата обращения: 05.10.2015).

7. ПАО «ППГХО» // В Краснокаменске подписаны еще два инвестиционных соглашения. URL: http://www.priargunsky.armz.ru/about/ news/?id=594\&p=2 (дата обращения: 05.05.2016).

8. Николай Похиленко: освоение Томторского месторождения в Якутии обойдется в 70 млрд руб. // Новости сибирской науки. - 2016. 31 март. URL: http://www.sib-science.info/ru/sbras/tomtor-30032016 (дата обращения: 03.05.2016).

9. Похиленко Н. П., Крюков В.А., Толстов А. В., Самсонов Н. Ю. Создание сильной редкоземельной промышленности России: без госкорпораций не осилить // ЭКО. - 2016. - № 8. - С. 25-36.

10. Продукция и услуги // Госкорпорация «Росатом». URL: http://www. rosatom.ru/production (дата обращения: 06.08.2015).

11. Добыча урана // Госкорпорация «Росатом». URL: http://www.rosatom.ru/production/mining (дата обращения: 06.08.2015).

12. Тайга инфо. Экономика // ППГХО выведут на безубыточную работу. URL: http://tayga.info/releases/2014/04/24/ 116398 (дата обращения: 10.05.2016).

13. Забmedia.ru // Представитель «Росатома»: ППГХО осталось «жить» 5 лет. URL: http://zabmedia.ru/news/75054/predstavitel_rosatoma_ppgho_ ostalos_zhit_5_let/ (дата обращения: 16.08.2015).

14. Крюков В.А., Толстов А. В., Афанасьев В. П., Самсонов Н.Ю., Крюков Я.В. Обеспечение российской промышленности высокотехнологичной сырьевой продукцией на основе гигантских месторождений Арктики - Томторского ниобий-редкоземельного и Попигайского сверхтвердого абразивного материала // Север и Арктика в новой парадигме мирового развития. Лузинские чтения - 2016 / Под общ. ред. Е. П. Башмаковой, Е. Е. Торопушиной; Кольский науч. центр РАН, Ин-т экон. проблем им. Г.П. Лузина Кольского, - Апатиты: ИЭП КНЦ PAH, 2016. - С. 204-206.

15. О топливной компании // Топливная компания «ТВЭЛ». URL: http:// www.tvel.ru/wps/wcm/connect/tvel/tvelsite/about (дата обращения: 07.08.2015).

16. Разделительно-сублиматный комплекс // Топливная компания «ТВЭЛ». URL: http://www.tvel.ru/wps/wcm/connect/tvel/tvelsite/about/ structure/RS_complex (дата обращения: 07.08.2015).

17. ОАО «АЭХК» - партнер для развития бизнеса [Электронный pecypc] // «AЭXK». URL: http://www.aecc.ru/attachments/article/334/ AECC_partner.pdf (дата обращения: 07.08.2015).

18. Сублиматный завод (СЗ) // «Сибирский химический комбинат». URL: http://www.atomsib.ru/ru/struktura-kombinata (дата обращения: 10.08.2015).

19. О предприятии // «Горно-химический комбинат». URL: http://www. sibghk.ru/company.html (дата обращения: 11.08.2015). 